VNU Journal of Science: Legal Studies Journal homepage: https://js.vnu.edu.vn/LS

Review Article

\title{
The Open Government and People Engagement in State Management
}

\author{
Vu Cong Giao, ${ }^{1, *}$, Le Phan Anh Thu ${ }^{2}$ \\ ${ }^{I}$ VNU School of Law, 144 Xuan Thuy, Cau Giay, Hanoi, Vietnam \\ ${ }^{2}$ Towards Transparency, 46 An Duong, Tay Ho, Hanoi, Vietnam
}

Received 13 August 2020

Revised 10 December 2020; Accepted 17 December 2020

\begin{abstract}
In order to mobilize people's involvement in the state management in a practical, effective and sustainable manner, appropriate strategies and measures are required. One of the most comprehensive and effective measures among which is applying the Open Government model. The paper analyzes theoretical asspects and best practices of some countries on the relationship between citizen involvement and the open government model, thereby draws some suggestions for Vietnam in applying this model to promote and improve the efficiency of people's engagement in state management in Vietnam in the coming years.
\end{abstract}

Keywords: Open government, state management, Vietnam.

\footnotetext{
* Corresponding author.

E-mail address: giaovnu@gmail.com

https://doi.org/10.25073/2588-1167/vnuls.4316
} 


\title{
Chính quyền mở và sự tham gia của người dân vào quản lí nhà nước
}

\author{
Vũ Công Giao ${ }^{1, *}$, Lê Phan Anh Thu² \\ ${ }^{1}$ Khoa Luật, Đại học Quốc gia Hà Nội, 144 Xuân Thủy, Cầu Giấy, Hà Nội, Việt Nam \\ ${ }^{2}$ Tổ chức Hướng tới Minh bạch, 46 An Duoong, Tây Hồ, Hà Nội, Việt Nam \\ Nhận ngày 13 tháng 8 năm 2020 \\ Chỉnh sửa ngày 10 tháng 12 năm 2020; Chấp nhận đăng ngày 17 tháng 12 năm 2020
}

\begin{abstract}
Tóm tắt: Để huy động sự tham gia của người dân vào hoạt động quản lý nhà nước một cách thực chất, hiệu quả và bền vững, cần phải có những chiến lược và biện pháp phù hợp. Một trong những biện pháp có tính toàn diện và triệt để nhất đó là thực hiện mô hình chính quyền mở (Open Government) $^{1}$. Bài viết những phân tích mối quan hệ giữa sự tham gia của người dân và mô hình chính quyền mở từ góc độ lý thuyết và kinh nghiệm thực tế của một số quốc gia, qua đó nêu ra một số gợi ý với Việt Nam trong việc áp dụng mô hình này để thúc đẩy và nâng cao hiệu quả sự tham gia của người dân vào hoạt động quản lý nhà nước ở Việt Nam trong những năm tới..
\end{abstract}

Tù khóa: Chính quyền mở, quản lý nhà nước, Việt Nam.

\section{Chính quyền mở, Sáng kiến Đối tác Chính quyền mở (OGP) và ý nghĩa với việc thúc đẩy sự tham gia của người dân vào quản lý nhà nước}

Bước sang thế kỷ 21, các quốc gia ngày càng nhận thức được tầm quan trọng của sự tham gia của người dân và vào quá trình xây dựng và thực hiện chính sách công. Chính vì vậy, trong vài thập kỷ gần đây, khái niệm về Chính quyền mở (Open Govenment) với văn hóa quản lý mở ngày càng được nói đến nhiều hơn trên thế giới.

Trong thực tế, chính quyền mở không phải là khái niệm hoàn toàn mới, mà đã được đề cập từ thời kỳ Khai sáng ở châu Âu [1]. Tuy nhiên, nếu như trước đây khái niệm chính quyền mở đơn thuần chỉ sự công khai trong hoạt động của bộ máy nhà nước, thì ngày nay, thuật ngữ này còn hàm nghĩa một bộ máy chính quyền biết lắng nghe, tôn trọng tâm tư, nguyện vọng, luôn

\footnotetext{
"Tác giả liên hệ.

Địa chỉ email: giaovnu@gmail.com

https://doi.org/10.25073/2588-1167/vnuls.4316
}

trăn trở làm những gì tốt nhất để đáp ứng nhu cầu của người dân và thúc đẩy sự phát triển của xã hội [2].

Từ một góc độ khác, thuật ngữ "mở" nêu ở trên là một khái niệm có vẻ mới, nhưng thực tế có liên quan rất mật thiết đến các nguyên tắc dân chủ truyền thống - theo đó chính quyền là do người dân lập ra, phải phục vụ nhân dân và chịu sự kiểm soát của nhân dân. Chính quyền "mở" - do vậy là cần thiết để đảm bảo quyền được biết và tham gia của người dân.

Theo Tổ chức Hợp tác và Phát triển Kinh tế $(\mathrm{OECD})$, sự tham gia của người dân

\footnotetext{
${ }^{1}$ Open Government thường được chuyển ngữ sang tiếng Việt là "Chính phủ mở" (kể cả trong các tài liệu của TT). Tuy nhiên, theo nhóm nghiên cứu, cách hiểu như vậy là chưa đầy đủ, vì Open Government hàm ý toàn bộ bộ máy chính quyền mở (gồm các cơ quan lập pháp, hành pháp, tư pháp) chứ không chỉ riêng Chính phủ (là cơ quan hành pháp, một bộ phận của chính quyền). Vì vậy, trong báo cáo này, chúng tôi sử dụng khái niệm "Chính quyền mở" để chỉ Open Government. Như vậy, khái niệm "Chính quyền mở" trong báo cáo này tương đương với khái niệm "Chính phủ mở" đã và có thể sẽ được dùng trong các tài liệu khác, khi mà "Chính phủ mở" cũng được dùng để chỉ Open Government.
} 
vào quản lý nhà nước là một trong các nguyên tắc nền tảng để xây dựng nên chính quyền mở. Nguyên tắc này gắn với những yêu cầu về sự minh bạch, liêm chính, và trách nhiệm giải trình của chính quyền [3].

Theo Chính phủ Canada, khái niệm chính quyền "mở" nhấn mạnh sự chủ động trong hành động của chính quyền, hay là việc làm cho chính quyền trở nên dễ tiếp cận với người dân, [4] còn theo Chính phủ Phần Lan, chính quyền mở là: "nền quản trị minh bạch, thông tin và dịch vụ công dễ tiếp cận, và một chính quyền đón nhận các ý tưởng, yêu cầu và nhu cầu mới”" [5], từ đó đem lại công cụ cải thiện chất lượng dân chủ để đáp ứng tốt hơn nhu cầu của người dân. Trong khi đó, theo Chính phủ Hoa Kỳ, chính quyền mở tức là xoá bỏ văn hóa bí mật và các hoạt động thiếu minh bạch trong hệ thống quản trị của quốc gia, ví dụ như việc những nhà vận động hành lang gây ảnh hưởng không chính đáng lên các chủ thể công quyền, hay sự khuất tất khi chi tiêu tiền thuế của người dân $[6], \ldots$

Ở Việt Nam, khái niệm chính quyền mỏ mới chỉ được một số tác giả đề cập từ năm 2014 (gọi là "chính phủ mở"), xem đó như là "con đường phía trước" [1] để cải cách nền hành chính công [7]. Dù vậy, cần thấy rằng trước đó Đảng Cộng sản và Nhà nước Việt Nam đã đề cao quyền làm chủ của người dân và nhiều lần nhấn mạnh sự cần thiết phải xây dựng môi trường và điều kiện để chính sách của nhà nước trở lên công khai hơn, có sự tham gia nhiều hơn và đáp ứng tốt hơn các nhu cầu của người dân đây thực chất là những yếu tố nền tảng của chính quyền mở. Việc Chính phủ ban hành Nghị định về Quy chế Dân chủ Cơ sở vào năm 1998 (được thay thế bằng Nghị định 04/2015/NĐ-CP), sau đó là việc Uỷ ban Thường vụ Quốc Hội thông qua Pháp lệnh về dân chủ cơ sở vào năm 2007, và gần đây là việc Quốc Hội thông qua Luật Tiếp cận thông tin năm 2015, có thể xem là những dấu mốc quan trọng trong vấn đề này ở Việt Nam.

Nói tóm lại, từ những phân tích ở trên, có thể hiểu chính quyền mở chính là xu hướng cải cách quản trị nhà nước nhằm tạo điều kiện để người dân có thể tham gia thực chất và hiệu quả vào các hoạt động quản lý xã hội, đặc biệt là việc hoạch định và thực thi chính sách công của các quốc gia.

Trong bối cảnh nêu trên, Sáng kiến Đối tác Chính quyền mở (Open Government Parnership - OGP) đã được công bố vào năm 2011, bởi 8 nhà lãnh đạo quốc gia và 9 nhà lãnh đạo của các tổ chức xã hội lớn của các quốc gia đó, bao gồm Brazil, Indonesia, Mexico, $\mathrm{Na} \mathrm{Uy}$, Phillippines, Nam Phi, Anh và Mỹ [2]. Việc đa số thành viên sáng lập OGP là các nước đang phát triển (Brazil, Indonesia, Mexico, Phillippines, Nam Phi) cho thấy OGP không phải là sáng kiến của các nước phát triển ở phương Tây áp đặt cho các nước đang phát triển; còn việc đồng thời có sự tham gia của đại diện của cả chính quyền và các tổ chức xã hội của những nước sáng lập cho thấy OGP thể hiện sự chia sẻ tầm nhìn giữa chính quyền và các tổ chức xã hội, hay rộng hơn, là giữa chính quyền với người dân [2].

Khởi đầu vào năm 2011 với chỉ có 8 nước thành viên nhưng tính đến tháng 7/2020, OGP đã có 78 nước chính quyền trung ương, 20 chính quyền địa phương tham gia và hàng ngàn tổ chức xã hội là đối tác [8]. Trong số các quốc gia thành viên $\mathrm{OGP}$ hiện nay, có $2 / 3$ là các nước đang phát triển, trong đó có nhiều nước châu Á như Indonesia, Philippines, Papua New Guinea và Hàn Quốc,... Sự phát triển rất nhanh của OGP, theo lý giải của Bộ trưởng Indonesia Kuntoro Mangkusubroto, là do "OGP tăng cường sự cởi mở nhằm hướng tới mục tiêu chung là một nhà nước quản trị tốt" - điều mà hầu hết các quốc gia trên thế giới đều đang hướng tới [2].

Dù vậy, cần thấy rằng $\mathrm{OGP}$ hiện tại chưa phải là một tổ chức quốc tế, mà mới chỉ là một mạng lưới cho phép các quốc gia thành viên có thể hỗ trợ, giúp đỡ lẫn nhau trong cải cách bộ máy nhà nước theo mô hình chính quyền mở.

OGP hoạt động dựa trên các nguyên tắc cơ bản đó là: i) tăng cường cung cấp thông tin cho công chúng về các hoạt động của nhà nước; ii) hỗ trợ sự tham gia của người dân vào hoạt động quản lý nhà nước; iii) áp dụng các tiêu chuẩn cao nhất về tính liêm chính và chuyên nghiệp cho toàn bộ hệ thống quản trị nhà nước (QTNN); iv) tăng cường khả năng tiếp cận với 
các công cụ công nghệ hiện đại nhằm nâng cao tính công khai và trách nhiệm giải trình của bộ máy nhà nước [9].

Từ những nguyên tắc trên, có thể thấy OGP gắn kết chặt chẽ với sự tham gia của người dân vào quản lý nhà nước. Một trong những nguyên tắc cơ bản của OGP đề cập trực tiếp đến vấn đề này, trọng khi các nguyên tắc khác đều có liên quan mật thiết đến sự tham gia của người dân vào quản lý nhà nước. Như vậy, việc một nước gia nhập OGP sẽ thúc đẩy sự tham gia của người dân vào quản lý nhà nước lên một bước mới, có tính chất hệ thống, toàn diện, liên tục, hiệu lực, hiệu quả và bền vững hơn rất nhiều so với trước đó.

\section{Yêu cầu về bảo đảm sự tham gia của người dân trong Sáng kiến Đối tác Chính quyền mở (OGP)}

Tuyên bố OGP đã thể hiện cam kết mạnh mẽ của các nước thành viên trong việc tăng cường sự tham gia của người dân vào giải quyết các vấn đề trong khu vực công, cũng như trong việc thúc đẩy không gian hợp tác giữa người dân và các tổ chức xã hội với Nhà nước. Minh chứng là một trong bốn lĩnh vực quan trọng mà sau này trở thành tiêu chí xét tư cách thành viên hợp lệ của các quốc gia gia nhập OGP chính là Sự tham gia của người dân. Các tiêu chí khác (bao gồm: Công khai ngân sách, Ban hành Luật chống tham nhũng, Ban hành Luật tiếp cận thông tin) cũng có sự gắn bó chặt chẽ và tác động trực tiếp đến tiêu chí về Sự tham gia của người dân.

Theo quy định của OGP, các quốc gia có thể đạt được tổng cộng tối đa 16 điểm đánh giá kết quả thực hiện trên 4 tiêu chuẩn của chính quyền mở (tạo nên Tiêu chí tư cách hợp lệ cốt lõi). Tuy nhiên, do có những thước đo không áp dụng được cho tất cả các quốc gia nên một số nước chỉ được đánh giá trên 3 tiêu chí, vì thế số điểm tối đa có thể đạt được là 12 điểm. Để có thể tham gia OGP, các quốc gia phải đạt được Tiêu chí tư cách hợp lệ cốt lõi với điểm số tối thiểu bằng $75 \%$ của tổng số điểm có thể có (ví dụ: 12 trên 16 hoặc 9 trên 12) [10].

OGP chú trọng đến một số quyền con người có tầm quan trọng nền tảng trong việc tạo nên một không gian cho sự tham gia của người dân vào quản lý nhà nước, đó là quyền tự do hội họp, tự do lập hội, và tự do biểu đạt. Vì vậy, phương pháp tính điểm "Sự tham gia của người dân" sử dụng chỉ số Quyền tự do dân sự (Civil Liberties) có thang điểm từ 0 đến 10 . Chỉ số này thuộc bộ chỉ số Dân chủ của the Economist Intelligence Unit (gọi tắt là EIU) - cơ quan nghiên cứu và phân tích thuộc cùng tập đoàn với tờ tạp chí danh tiếng The Economist (Nhà Kinh tế, ở Anh). OGP tính bốn điểm cho quốc gia đạt trên 7.5/10 chỉ số quyền tự do dân sự, ba điểm cho quốc gia đạt trên 5 , hai điểm cho quốc gia đạt trên 2.5 và không điểm cho quốc gia đạt từ 2.5 trở xuống. Vào thời điểm tháng 7/2018, Việt Nam được 2.65 điểm cho chỉ số Quyền tự do dân sự, tức là 2 điểm OGP cho tiêu chí Sự tham gia của người dân. Kể từ khi OGP bắt đầu tính điểm vào năm 2010, Việt Nam đã tăng từ 1 lên 2 điểm OGP cho tiêu chí này vào năm 2016, và vẫn giữ điểm số đó trong 04 năm qua. Các chỉ số khác và điểm tương ứng của Việt Nam trong bộ Chỉ số dân chủ bao gồm: Tiến hành bầu cử công bằng và tự do $(0.0)$, Sự hoạt động của chính quyền (3.21), Việc tham gia chính trị (3.89), và Văn hóa chính trị (5.63).

Gần đây nhất, ngày 22/1/2020, EIU đã công bố Chỉ số Dân chủ mới nhất (Democracy Index 2019), theo đó các điểm số của Việt Nam giữ nguyên không đổi nhưng thứ hạng đã tăng từ 139 lên 136 trong tổng số 167 quốc gia được xếp hạng [11].

Với các cam kết trong sứ mệnh của mình là đảm bảo các quốc gia tham gia OGP sẽ tôn trọng và thực thi các quy chuẩn và giá trị trong Tuyên bố Chính quyền mở, từ ngày 20/9/2017, OGP còn bổ sung thêm Bài kiểm tra giá trị để đánh giá cách thức đối xử của chính quyền với người dân. Qua đó, OGP yêu cầu ngoài Tiêu chí tư cách hợp lệ cốt lõi, tất cả các quốc gia thành viên phải vượt qua được bài Kiểm tra giá trị bằng cách đạt được ít nhất $3 / 4$ điểm của ít nhất một trong hai chỉ số liên quan đến xã hội công 
dân, mà được tính dựa trên dữ liệu từ bộ Các chỉ số về Dân chủ (Varieties of Democracy, gọi tắt là V-Dem) - một trong các dự án thu thập dữ liệu khoa học xã hội lớn nhất thế giới với hơn 350 chỉ số từ ý kiến chuyên môn của gần 3.000 chuyên gia ở các nước được đánh giá. Hai chỉ số được lựa chọn làm tiêu chí cho Bài kiểm tra giá trị của OGP là:

- "Sự thành lập và giải thể của các tổ chức xã hội" (CSO Entry and Exit): Chỉ số này nhằm đánh giá mức độ thuận lợi của pháp luật quốc gia với việc thành lập và giải thể các tổ chức xã hội, được cấu trúc từ 0 - 4 điểm, trong đó tương ứng với 0 : hoàn toàn không thuận lợi, 1 : rất không thuận lợi, 2: thuận lợi vừa phải, 3: thuận lợi, và 4: rất thuận lợi;

- "Sự kiểm soát các tổ chức xã hội" (CSO Repression): Chỉ số này nhằm đánh giá mức độ kiểm soát của các quốc gia với các tổ chức xã hội; cũng được cấu trúc gồm 5 mức từ $0-4$, tương ứng với 0 : nghiêm trọng, 1: đáng kể, 2 : vừa phải, 3 : yếu, và 4 : không kiểm soát.

Bên cạnh đó, với phương pháp luận đa chiều, V-Dem còn chỉ ra sự liên kết giữa 2 chỉ số nêu trên với các chỉ số khác về độ "mở" của chính quyền đối với các tổ chức xã hội khi xếp chung trong bộ 06 chỉ số về Tự do hội họp (Freedom of Association Index), bao gồm 02 mục này và 04 mục khác về các đảng chính trị. Chỉ số Tự do hội họp lại thuộc bộ chỉ số về Dân chủ Bầu cử (V-Dem Electoral Democracy Index - EDI), gồm các chỉ số tự do biểu đạt, tự do hội họp, tỉ lệ người dân đi bầu, bầu cử minh bạch, và mức độ trao quyền cho các quan chức được bầu ra.

Quy chiếu với hai tiêu chí trong Bài kiểm tra giá trị của OGP nêu trên, Việt Nam được 1 điểm cho mỗi mục, kết quả hiện là chưa đạt [12]. Tuy nhiên, đáng lưu ý là Việt Nam đã từng đạt được 2 điểm cho cả 2 mục này vào năm 2017, nhưng sau đó đã giảm đi vào năm 2018, cho thấy Việt Nam không phải không có khả năng bảo đảm các tiêu chí này.

Theo báo cáo V-Dem mới nhất 2019, chỉ số EDI của Việt Nam là 0.224 , xếp thứ 154/179 quốc gia được xếp hạng và được xem là mốc đánh dẩu sự tăng trưởng đáng kể trong 10 năm qua.
Như đã đề cập, xét tất cả các chiều kích của OGP, có thể thấy trọng tâm là sự tham gia của người dân vào quá trình hoạch định và thực thi chính sách công. Thông qua cách đánh giá với tiêu chí "sự tham gia của người dân" và "bài kiểm tra giá trị", OGP cũng đồng thời đưa ra các chuẩn mực cho sự tham gia của người dân, bao gồm bảo đảm các quyền tự do dân sự và nguyên tắc khoan dung với xã hội công dân. Mức độ tự do cao của xã hội công dân, đến lượt nó, lại giúp chính quyền xử lý tốt hơn với các rủi ro nghiêm trọng có thể xảy ra trong hệ thống quản trị công, ví dụ như tham nhũng. Với sự liên quan mật thiết như vậy, Tổ chức Minh bạch Quốc tế (TI) cũng sử dụng V-Dem và EIU như là 2 trong 8 nguồn dữ liệu để tính Chỉ số Cảm nhận Tham nhũng (CPI) hàng năm của các quốc gia.

\section{Một số bài học kinh nghiệm tốt về huy động sự tham gia của người dân trong OGP và giá trị tham khảo cho Việt Nam}

Với các đặc điểm của chính quyền mở, bao gồm minh bạch, sự tham gia của người dân, trách nhiệm giải trình, và đổi mới đi cùng với ứng dụng công nghệ thông tin, mỗi quốc gia thành viên OGP có trách nhiệm xây dựng kế hoạch hành động theo định kỳ 2 năm nhằm hiện thực hóa các cam kết của mình về các vấn đề đó.

Như đã đề cập, sau gần 10 năm thành lập, hiện đã có 78 quốc gia và 20 chính quyền địa phương, đại diện cho hơn 2 tỷ người, đã tham gia OGP. Những thành viên của OGP đã đưa ra hơn 100 kế hoạch hành động với hơn 3.800 cam kết để xây dựng chính quyền mở. Đúng như mục tiêu của mình, OGP đã trở thành một nền tảng, một đầu mối của các nhà cải cách từ khắp nơi trên thế giới để tìm đến, chia sẻ ý tưởng quản lý, và cùng nhau thực hành. Rất nhiều bằng chứng đã được ghi lại, rất nhiều quá trình thực hiện cam kết của các chính quyền đã được tài liệu hóa, giúp cho OGP cũng trở thành một "túi khôn" cho cộng đồng, các quốc gia thành viên cũng như còn chưa phải là thành viên như Việt Nam. 
Dù tác động của một chính sách được thực thi thường phải mất nhiều năm để có thể đánh giá hiệu quả, song OGP đã cố gắng theo sát, ghi chép, và tài liệu hóa được rất nhiều bằng chứng, và đúc rút rất nhiều bài học kinh nghiệm. Những kết quả được công bố có ý nghĩa tham khảo cho Việt Nam ở các mặt sau đây, cho thấy sự tham gia của người dân có thể giúp nâng cao chất lượng dịch vụ công, ngăn ngừa tham nhũng, giúp tiết kiệm ngân sách nhà nước, giúp khu vực tư phát triển kinh doanh, và quan trọng nhất, giúp tăng niềm tin của người dân vào chính quyền.

Thư nhất, sụ tham gia của người dân là động lực chính yếu để cái thiện chẩt luợng dịch vu công: Các cam kết của chính quyền mở đã giúp gia tăng sự tham gia của người dân vào nhiều giai đoạn cung cấp dịch vụ công, từ khâu xác định ưu tiên, phân bổ nguồn lực, thiết kế chính sách, dịch vụ cho đến thực thi và theo dõi, giám sát nhà cung ứng, nhờ vậy chất lượng dịch vụ công đã được nâng cao rõ rệt và chi phí giảm đi đáng kể. Ví dụ, ở Brazil, việc quản lý ngân sách có sự tham gia của người dân địa phương đã giúp tăng ngân sách cho dịch vụ vệ sinh dịch tễ lên $20-30 \%$ và giảm tỉ lệ tử vong ở trẻ sơ sinh. Sáng kiến mời phụ huynh tham gia đánh giá chất lượng trường học ở Pakistan đã giúp chất lượng dạy và học được cải thiện, số học sinh ghi danh tăng $4.5 \%$ và giảm chi phí trường tư $17 \%$. Bài học được đúc kết từ thực tiễn ở nhiều nước cho thấy việc công khai thông tin và được tham gia đã làm tăng nhận thức của người dân về các vấn đề của quản lý công, bên cạnh việc tăng cường kiểm tra, giám sát để giúp quyền lực được chia sẻ, khuyến khích báo chí hoạt động, và gây sức ép buộc bên cung cấp dịch vụ phải cải thiện chất lượng [13, tr.20]. "Nỗ lực của chúng tôi trong việc chia sẻ một lượng lớn thông tin đã giúp cải thiện đáng kể việc tiếp cận với các hợp đồng của chính quyền, đồng thời giúp tạo ra và tăng cường các cơ chế để xã hội công dân có thể giám sát độc lập" - đó là phát biểu của Santiago Jure, Giám đốc cơ quan quản lý các hợp đồng của Chính phủ Paraguay về dự án cổng thông tin đấu thầu minh bạch kèm tập huấn kĩ năng điều tra cho nhà báo. Hệ thống này kể từ khi được thiết lập đã giúp tiết kiệm ít nhất 61 triệu đô la Mỹ chi phí văn phòng phẩm, và các nhà báo đã sử dụng nó để điều tra các khoản chi bất hợp lý của các bộ ban ngành, ví dụ như việc mua bàn ghế với giá gấp 10 lần thị trường [13].

Thư hai, trong công tác phòng, chống tham nhũng, sức mạh tù việc giám sát của nguời dân lại càng đóng vai trò quan trọng, đặc biệt là sư giám sát của báo chí và khu vưc ngoài nhà nước: Nigeria và Vương quốc Anh là hai trong số các nước chống tham nhũng thành công nhất trong OGP chính nhờ vào việc xây dựng các liên minh giám sát từ người dân. Sau khi nhận ra các bất cập trong việc mua sắm công, Nigeria đã đứng ra thành lập tổ giám sát bao gồm một tổ chức dân sự, một trường đại học, và một cơ quan báo chí để theo dõi quy trình đấu thầu việc xây dựng các trung tâm chăm sóc sức khỏe mới ở nước này. Mới đây, họ đã tự tin tuyên bố là sẽ ứng dụng mô hình này để xây dựng thêm 10.000 cơ sở y tế mới. Trong khi đó, Vương quốc Anh đã dựa vào các tổ chức xã hội và các chuyên gia tình nguyện để tìm ra ai là chủ sở hữu thật sự của các công ty, đặc biệt là các công ty nhận được hợp đồng với chính quyền, qua đó xác định được ai chịu trách nhiệm giải trình về hoạt động của các công ty đó [13].

Thư ba: Ngân sách nhà nuớc có thể tiết kiệm được rất nhiều nếu thiết lập được hệ thống mua sắm công "mờ", qua đó người dân giám sát, phản hồi dựa trên thông tin kịp thời do chính quyền cung cấp và giúp phát hiện ra những sai phạm, đồng thời tăng tính cạnh tranh của các nhà thầu. Nghiên cứu của TI ở Vương quốc Anh cho thấy, việc đấu thầu công khai có thể tiết kiệm ngân sách đến $30 \%$ ở các quốc gia thu nhập cao, và đến $50 \%$ ở các quốc gia các thu nhập thấp và trung bình [14]. Một ví dụ khác, hệ thống đấu thầu công khai qua mạng đã giúp thành phố Pro-Zorro ở Ukraine tiết kiệm được 350 triệu euro và tăng $550 \%$ số nhà cung ứng từ khi áp dụng vào năm 2017 [13, tr.37]. Chính phủ Philippines cũng đã tiết kiệm được xấp xỉ 1.4 triệu USD cho việc đấu thầu dịch vụ cung cấp giáo trình, và giảm giá sách xuống 
hơn $40 \%$, đồng thời cắt ngắn quy trình đấu thầu từ 24 xuống 12 tháng.

Xét rộng hơn, trong OGP, hơn 30 quốc gia và thành phố đã thiết lập được quy trình đấu thầu "mở", nhấn mạnh đến cả việc công khai thông tin ở tất cả các bước từ mở thầu đển khi kết thúc thầu, và tạo điều kiện cho người dân tham gia giám sát vào mọi quy trình đấu thầu.

Ở Việt Nam trong thực tế cũng đã áp dụng đấu thầu qua mạng từ năm 2016. Bộ Kế hoạch Đầu tư cho biết tồ chức đấu thầu qua mạng đã giúp tiết kiệm từ $1 \%$ đến gần $2 \%$, tương đương hàng nghìn tỷ đồng tổng giá gói thầu so với phương pháp truyền thống trong giai đoạn 2016-2018 [15]. Bộ cũng cho biết cơ sở dữ liệu đấu thầu của Việt Nam áp dụng Tiêu chuẩn Dũ liệu Hợp đồng Mở [16] có thể dễ dàng được đọc hiểu và chia sẻ. Mới đây, Văn phòng Chính phủ đã cho ra mắt Cổng Dịch vụ công quốc gia, bên cạnh việc cung cấp thông tin và dịch vụ công trực tuyến, Cổng cũng hỗ trợ việc người dân tham gia giám sát, đánh giá việc giải quyết thủ tục hành chính thông qua tiếp nhận và xử lý phản ánh, kiến nghị của các cá nhân và tổ chức [17]. Đây là tín hiệu tích cực cho thấy Việt Nam đang dần hướng đến chính quyền mở và đã sã̃n sàng để thực hiện các bước phát triển và nâng cao hơn, ví dụ truyền thông cho doanh nghiệp và công chúng về cổng thông tin, hay bắt đầu nhận phản hồi và khiếu nại qua cổng thông tin điện tử.

Thư tu, chủ động công khai thông tin và tăng cường úng dụng công nghệ có thể gỡ bỏ rất nhiều rào cản với sự tham gia của nguời dân: Đây cũng là các giá trị và nguyên tắc mà OGP nhấn mạnh: sự sẵn có của thông tin, sự tham gia, sự trong sạch, và sự đổi mới công nghệ. Tất cả đều nhằm làm tăng độ mở của chính quyền và khuyến khích người dân tham gia vào quản lý nhà nước. Thông tin cung cấp trên cổng dữ liệu đấu thầu cần bao gồm các nhà thầu đã từng nộp và những người trúng thầu, giá bỏ thầu chi tiết, đơn giá, giá thị trường được thể hiện dưới dạng dữ liệu mở dễ chia sẻ.

Về vấn đề này, kinh nghiệm từ Bang Virginia (Hoa Kỳ) cho thấy họ đã tiết kiệm được 450 triệu USD trong giai đoạn 2001-2015 và 30 triệu USD chỉ trong năm 2015 [13, tr.40].
Ở Ân Độ, cơ chế thực hiện và công khai kiểm toán xã hội bắt buộc ở một số bang đã giúp nâng cao chất lượng các chương trình chính sách Nhà nước [13]. Ở Indonesia, việc công bố báo cáo kiểm toán các công trình cơ sở hạ tầng đã giúp làm giảm đến $1 / 3$ tỉ lệ thất thoát - tương đương $8 \%$ ngân sách xây dựng. Ở Hàn Quốc, việc công khai thông tin chất lượng nước đã làm tăng niềm tin của người dân vào hệ thống cung cấp nước. Ở Estonia (được coi là một trong các nước chống tham nhũng thành công nhất trong khối Xô-viết cũ), nhà nước đã ban hành và thực thi mạnh mẽ một loạt cải cách như chính quyền điện tử và luật tiếp cận thông tin, vì đó đã giúp hạn chế đáng kể tình trạng tham nhũng.

Thư năm, sự tham gia của ngườ dân đem lại sư minh bạch cho hệ thống quản lý nhà nước, và giúp tăng niềm tin vào chính quyền: Nghiên cứu của $\mathrm{OECD}$ vào năm 2009 cho thấy niềm tin của người dân tăng lên rõ rệt khi họ được gửi và nhận được phản hồi chu đáo từ các cơ quan công quyền [18]. Ví dụ, năm 2012, khủng hoảng niềm tin xảy ra ở Canada liên quan đến ngành công nghiệp nuôi trồng thủy sản, khi người dân cho rằng đây là nguyên nhân khiến loài cá hồi tự nhiên biến mất. Căng thẳng càng tăng lên khi một loạt trang trại nuôi cá mới được cho phép xây dựng và ngư dân lo ngại họ sẽ bị mất sinh kế. Hơn 40 tổ chức đại diện lên tiếng đòi chính quyền phải giải thích về vụ việc. Để giải quyết, chính quyền đã lập ra cơ chế đối thoại mở, mời tất cả các bên liên quan và các chuyên gia tham gia vào quá trình lập chính sách dựa trên bằng chứng khoa học, đối thoại cẩn thận, và có sự theo dõi của công chúng. Dựa trên khuyến nghị từ các cuộc thảo luận công khai, chính quyền đã xây dựng được quy định mới, đồng thời củng cố niềm tin của người dân vào năng lực hoạt động của chính quyền $[13$, tr.61]. Hơn thế, việc này còn giúp thu hút sự tham gia, đóng góp nhiều hơn của các cá nhân, tổ chức có năng lực vào hoạt động quản lý nhà nước. Đó là bởi khi hướng tới chính quyền mở và thực hiện các sáng kiến, biện pháp để tăng cường sự tham gia của người dân, nhà nước cũng đồng thời gửi đi một thông điệp mạnh mẽ rằng họ chủ động tạo điều kiện để 
người dân cùng tham gia xây dựng chính sách, chứ không chỉ chờ đợi người dân tự tìm đến.

Nhìn chung, thông qua việc thực thi cam kết chính quyền mở, các nước tham gia OGP đã đạt được rất nhiều thành tựu. Tổng kết chặng đường 08 năm kể từ khi thành lập, vào tháng 6 năm 2019, OGP đã công bố báo cáo đánh giá đầu tiên của mình. Báo cáo được xây dựng dựa trên dữ liệu thu thập bởi Cơ quan Đánh giá Độc lập (IRM) và các nguồn thứ ba, có tên gọi "Dân chủ vượt lên trên thùng phiếu" [2]. Bản báo cáo đã khái quát và phân tích hiệu quả tác động của cam kết chính quyền mở, đồng thời để trả lời câu hỏi quan trọng nhất đối với chính quyền mở đó là: liệu "mở" có giúp chính quyền minh bạch, hiệu quả, có trách nhiệm giải trình, và có sự tham gia hơn hay không? Các kết quả đưa ra trong báo cáo đã giúp đưa ra một câu trả lời chắc chắn: minh bạch hơn sẽ đem lại các kết quả kinh tế - xã hội tốt hơn, với hàng ngàn câu chuyện hành động của các quốc gia trong OGP đã minh chứng cho điều đó. Thông qua OGP, các quốc gia đã thật sự hành động để "mở" chính quyền, qua việc lập kế hoạch quản lý chung với các chủ thể ngoài nhà nước, và các kết quả hành động được đánh giá bởi người dân. Điều này đã thúc đẩy mạnh mẽ trách nhiệm giải trình của nhà nước với công dân.

\section{Kết luận}

Trong thế kỷ 21, bảo đảm sự tham gia của người dân vào quản lý nhà nước đã trở thành một yêu cầu quan trọng bậc nhất của các quốc gia. Tuy nhiên, hình thức, phạm vi và mức độ sự tham gia của người dân vào quản lý nhà nước phụ thuộc rất nhiều vào mô hình quản trị của mỗi nước. Chính quyền mở có thể xem là một dạng mô hình quản trị quốc gia hiện đại, thể hiện chiều hướng phát triển của các nhà nước trong thế giới đang chuyển đổi rất nhanh chóng ở thế kỷ 21. Sự phát sinh, phát triển của mô hình chính quyền mở là do nhiều yếu tố khách quan chi phối, và là vấn đề có tính quy luật. Điều đó có nghĩa là muốn hay không thì các quốc gia trên thế giới cũng sẽ bị cuốn hút vào việc chuyển đổi quản trị quốc gia theo mô hình chính quyền mở.

Mô hình chính quyền mở dựa trên một số nguyên tắc, trong đó bảo đảm sự tham gia một cách rộng rãi, thực chất và hiệu quả của người dân vào quản lý nhà nước là nguyên tắc cốt lõi. Các nguyên tắc khác cũng có liên quan và hỗ trợ cho nguyên tắc này. Vì thế, có thể xem chính quyền mở là chính quyền có người dân tham gia, dựa trên sự tham gia quản lý của người dân. Như vậy, việc chuyển đổi sang mô hình chính quyền mở sẽ đòi hỏi và thúc đẩy mạnh mẽ sự tham gia của người dân vào quản lý nhà nước.

Với tính chất là một thiết chế quốc tế mềm nhằm thúc đẩy mô hình chính quyền mở, OGP đem lại cơ hội mới cho việc đẩy mạnh sự tham gia của người dân vào quản lý nhà nước ở các quốc gia. Các tiêu chí gia nhập, đánh giá và tổ chức hoạt động của OGP nhìn chung đều xoay quanh sự tham gia của người dân vào quản lý xã hội cùng với nhà nước. Do vậy, OGP hỗ trợ đắc lực cho các quốc gia trong việc hội nhập quốc tế trong bối cảnh toàn cầu hoá.

Với Việt Nam, OGP thực chất không phải là một thiết chế quốc tế hoàn toàn mới, mà chỉ là sự bổ sung cho các thiết chế quốc tế tương tự mà Việt Nam đã tham gia, tiêu biểu là UNCAC, WTO, CTTPP và EVFTA ${ }^{2}$.

Việt Nam, trong bối cảnh đang thực hiện chương trình Nghị sự 2020 về phát triển bền vững, hoàn toàn có thể tham khảo các bài học kinh nghiệm của các quốc gia trong OGP và dần tiến tới việc trở thành thành viên OGP để cải thiện hệ thống và xây dựng một nền quản trị tốt, bao gồm một quá trình ra chính sách có thể tiên liệu được, cởi mở và dân chủ; một bộ máy thấm nhuần tính chuyên nghiệp; một hệ thống cơ quan nhà nước thực sự có trách nhiệm giải trình về những hành động của mình; và một xã hội công dân năng động, tham gia tích cực và hiệu quả vào các hoạt động quản lý nhà nước.






\section{Lời cảm ơn}

Bài viết này là một phần của báo cáo nghiên cứu có tiêu đề: "Tìm hiểu các cơ chế huy động sự tham gia của người dân và các tổ chức xã hội vào hoạt động quản lý nhà nước ở Việt Nam hiện nay" do Vũ Công Giao và Lê Phan Anh Thư thực hiện cho Tổ chức Hướng tới Minh bạch năm 2020, với sự hỗ trợ của Nguyễn Quang Đức.

Bài viết được củng cố từ tham luận cùng tên mà các tác giả gửi đến và có trong Kỷ yếu Hội thảo "Sự tham gia của xã hội vào quản trị nhà nước và phòng, chống tham nhũng" do Khoa Luật ĐHQGHN tổ chức vào ngày 28 tháng 7 năm 2020.

\section{Tài liệu tham khảo}

[1] Nguyễn Thị Kiều Viễn, "Chính phủ mở - con đường phía trước”, VietnamNet ngày 7/01/2015, tại: https://vietnamnet.vn/vn/thoi-su/chinh-phumo-con-duong-phia-truoc-215384.html.

[2] Vũ Công Giao (2019). Sáng kiến đối tác Chính phủ mở và ý nghĩa với Việt Nam, Tạp chí Nghiên cứu Lập pháp, số 2+3/2019, ngày 13/08/2019. Xem thêm về OGP tại

https://www.opengovpartnership.org/about/aboutogp.

[3] OECD, Open Government, https://www.oecd.org/gov/open-government/, truy cập 22/1/2020.

[4] Government of Canada, Open Government, https://open.canada.ca/en, truy cập 22/1/2020.

[5] Government of Finland, Open Government, https://avoinhallinto.fi/assets/files/2018/10/ENGSivu-2.pdf, truy cập 22/1/2020.

[6] The White House, About Open Government, https://obamawhitehouse.archives.gov/open/about truy cập 22/1/2020.

[7] Lê Trung Nghĩa (2018), Hiểu đúng về chính phủ Mở, Tia Sáng, http://tiasang.com.vn/-diendan/Hieu-dung-ve-chinh-phu-Mo-14077, truy cập $15 / 01 / 2020$.

[8] Nguồn: https://www.opengovpartnership.org/ourmembers/

[9] Tuyên bố về Chính quyền mở tại: https://www.opengovpartnership.org/opengovernment-declaration.

[10] OGP, Eligibility Criteria \& OGP Values Check Assessment, cập nhật 18/07/2019,

https://www.opengovpartnership.org/process/joini ng-ogp/eligibility-criteria/.

[11] The Economist Intelligence Unit (2020), Economic and geopolitical insight guiding the world's organisations,

http://www.eiu.com/Handlers/WhitepaperHandler .ashx?fi=Democracy-Index-

2019.pdf \&mode $=$ wp \& campaignid $=$ democracyind ex2019, truy cập 22/01/2020.

[12] V-Dem Institute (2019), Annual Democracy Report 2019 - Democracy Facing Global Challenges, https://www.vdem.net/media/filer_public/99/de/99dedd73-f8bc484c-8b91-44ba601b6e6b/v-

dem_democracy_report_2019.pdf, p.16.,truy cập 22/01/2020.

[13] OGP (2018), The Skeptical's Guide, https://www.opengovpartnership.org/wpcontent/uploads/2018/09/SKEPTICSGUIDE_20180710.pdf, trang 20.

[14] Transparency International UK (2017), Making the Case for Open Contracting in Healthcare Procurement, http://ti-health.org/wpcontent/uploads/2017/01/Making_The_Case_for_ Open_Contracting_TI_PHP_Web.pdf.

[15] Báo Đảng Cộng sản, http://dangcongsan.vn/kinhte/dau-thau-qua-mang-gop-phan-ngan-chan-tieucuc-tham-nhung-529049.html, truy cập lần cuối 03/04/2020.

[16] Open Contracting Partnership, https://www.opencontracting.org/data-standard/, truy cập lần cuối 03/04/2020.

[17] Giới thiệu về Cổng Dịch vụ công Quốc gia, https://dichvucong.gov.vn/p/home/dvc-gioithieu.html, truy cập lần cuối 03/04/2020.

[18] OECD (2009), Focus on Citizens: Public Engagement for Better Policy and Services, OECD Studies on Public Engagement, OECD Publishing, https://doi.org/10.1787/9789264048874-en.

[19] Open Government Partnership Secretariat (2019), Democracy Beyond The Ballot Box (1st edition), https://www.opengovpartnership.org/wpcontent/uploads/2019/09/Global-Report_Volume1.pdf, truy cập 20/01/2020. 